\title{
Nonsurround, nonuniform, biventricular-capable direct cardiac compression provides Frank-Starling recruitment independent of left ventricular septal damage
}

\author{
James Mau, BSc, MBBS,,${ }^{\text {ab,c }}$ Stuart Menzie, MBBS, FRACS, ${ }^{a}$ Yifei Huang, MD, PhD, ${ }^{\text {a }}$ \\ Michael Ward, MBBS, PhD, FRACP, ${ }^{\mathrm{b}, \mathrm{c}}$ and Stephen Hunyor, MBBS, MD, MTM, FRACP, FACC ${ }^{\mathrm{a}, \mathrm{b}, \mathrm{c}}$
}

\begin{abstract}
Objectives: Right ventricular (RV) function is compromised in $25 \%$ of left ventricular (LV) assist device recipients despite effective LV support. The risk of such dysfunction has been enhanced by an ischemic or undamaged interventricular septum; however, we found septal infarction to be paradoxically protective. We, therefore, evaluated the potential of nonsurround, nonuniform, biventricular-capable direct cardiac compression (DCC) (using the HeartPatch DCC) to overcome RV dysfunction in hearts with a normal or infarcted interventricular septum.
\end{abstract}

Methods: Ethanol ablation was used to create an interventricular septal infarction in 6 sheep, and 6 others served
as the control sheep. The load-independent and in-series RV response to DCC was assessed using sonomicrom-
eter heart dimension sensors. Triphenyltetrazolium perfusion delineated the septal damage.

Results: LV DCC caused a greater increase of the RV preload recruitable stroke work in the control sheep than in the study sheep $\left(190.6 \pm 23.5\right.$ and $135.0 \pm 40.8 \mathrm{erg} * 10^{\wedge} 3$, respectively, $\left.P<.001\right)$. In contrast, RV end-systolic elastance increased more in the septal-ablated sheep with RV DCC $(17.29 \pm 3.40 \mathrm{vs} 9.88 \pm 2.01 \mathrm{~mm} \mathrm{Hg} / \mathrm{mL}$ in the control sheep, $P<.001)$. Abnormal RV diastolic function before device insertion in the septal-ablated sheep was normalized with both passive DCC placement and after activation (RV diastolic relaxation constant $23.5 \pm$ 2.3 and $20.0 \pm 2.1 \mathrm{~ms}$, respectively, $P<.001)$. Both biventricular and RV DCC actuation increased the RV systolic pressure more in the septal-ablated sheep than in the control sheep $(37.9 \pm 6.3$ and $47.7 \pm 4.6 \mathrm{~mm} \mathrm{Hg}$ vs $29.7 \% \pm 4.8 \%$ and $40.3 \% \pm 8.3 \%$, respectively, $P<.001)$. In contrast, the RV end-systolic diameter decreased more during LV DCC $(70.1 \% \pm 15.9 \%$ vs $90.5 \% \pm 5.0 \%, P<.001)$.

Conclusions: The HeartPatch DCC support of LV and RV function results from improvement of the systolic septal-lateral fractional change that is not influenced by septal infarction. The latter attenuated LV to RV device energy delivery during LV patch actuation but enhanced RV energy delivery during RV patch actuation. This DCC technique can provide effective support in high-risk RV failure situations arising from left ventricular assist device use. (J Thorac Cardiovasc Surg 2011;142:209-15)

Implantation of left ventricular (LV) assist devices (LVADs) for the treatment of heart failure has increased in the postRandomized Evaluation of Mechanical Assistance in the Treatment of Congestive Heart failure (REMATCH) era, ${ }^{1-4}$ with several devices approved as destination therapy. ${ }^{2,5}$ However, major issues remain because of the risk of thromboembolism, bleeding, and pump failure, as well as the potential for intraoperative and early

\footnotetext{
From the Cardiac Technology Centre, ${ }^{\mathrm{a}}$ North Shore Heart Research Group, ${ }^{\mathrm{b}}$ and Department of Cardiology and Kolling Institute, ${ }^{\mathrm{c}}$ University of Sydney at Royal North Shore Hospital, Sydney, NSW, Australia.

J. Mau was supported by a Dora Lush Scholarship of the National Health and Medical Research Council and by the North Shore Heart Research Foundation.

Disclosures: Authors have nothing to disclose with regard to commercial support. Received for publication Nov 28, 2009; revisions received April 14, 2010; accepted for publication May 6, 2010; available ahead of print Dec 17, 2010.

Address for reprints: James Mau, BSc, MBBS, Cardiac Technology Centre, Level 12, Kolling Building, Royal North Shore Hospital, Pacific Hwy, St Leonards, Sydney, NSW 2065 Australia (E-mail: jmau@med.usyd.edu.au). $0022-5223 / \$ 36.00$

Copyright (C) 2011 by The American Association for Thoracic Surgery doi:10.1016/j.jtcvs.2010.05.057
}

postoperative right ventricular (RV) failure, which has affected up to $25 \%$ of device recipients. ${ }^{6-10}$ Recent reports have suggested the latter is of greater significance than previously thought, often requiring additional support for the right-sided circulation. ${ }^{11}$ An alternative technology-based approach to these shortcomings relies on epicardial systolic augmentation by direct cardiac compression (DCC), which avoids many of the drawbacks of the in-line blood-contacting biventricular assist devices. ${ }^{12}$

DCC has been implemented in various forms during the past 50 years, including a pneumatic-driven rigid heartencircling "cup" 13 and a "copulsation" device ${ }^{14}$ that assists the left and/or right ventricles. Despite improving the LV and RV cardiac output and myocardial energy efficiency, these devices have displayed static enhancement of ventricular function, without improvements to load-independent indexes and, thus, have relied on high-filling volumes to maintain a suitable mechanical therapeutic window. Furthermore, the heart-surrounding configuration of such devices is likely to constrain ventricular filling and impair 


$$
\begin{aligned}
& \text { Abbreviations and Acronyms } \\
& \begin{aligned}
\text { DCC } & =\text { direct cardiac compression } \\
\text { ED } & =\text { end-diastolic } \\
\text { Ees } & =\text { end-systolic elastance } \\
\text { ES } & =\text { end-systolic } \\
\text { ESPVR } & =\text { ES pressure/volume relationship } \\
\text { LV } & =\text { left ventricular } \\
\text { LVAD } & =\text { left ventricular assist device } \\
\text { MSPA } & =\text { main septal perforating artery } \\
\text { PRSW } & =\text { preload recruitable stroke work } \\
\text { PTSMA } & =\text { percutaneous transluminal septal } \\
& \text { myocardial ablation of the artery } \\
\text { RV } & =\text { right ventricular } \\
\text { SW } & =\text { stroke work }
\end{aligned}
\end{aligned}
$$

early diastolic relaxation. To overcome such shortcomings, we used a novel design consisting of independent nonsurround RV- and LV-apposed pumping chambers (HeartPatch-DCC device; Heart Assist Technologies, St Leonards, NSW, Australia; Figure 1), which has been shown to have potent ability to increase cardiac output ${ }^{15}$ and restore myocardial efficiency during pharmacologically induced heart failure. ${ }^{16}$ This device was implanted in sheep hearts with septal pathologic features, as previously described, ${ }^{17}$ to compare the RV in-series, load-independent, and geometric responses to that of previously studied inline mechanical LVAD unloading.

\section{MATERIALS AND METHODS}

A total of 15 Border-Leicester cross sheep (body weight, $59.0 \pm 7.1 \mathrm{~kg}$ ) were used in the present study, which was approved by the Institutional Animal Care and Ethics Committee. The sheep received humane care in compliance with the "Guide for the Care and Use of Laboratory Animals" prepared by the Institute of Laboratory Animals Resources, National Research Council, 1996. Anesthesia was induced by alfaxalone ( $5-10 \mathrm{mg} / \mathrm{kg}$ ) and maintained with $50 \%$ oxygen, $45 \% / 50 \%$ nitrous oxide, and $\sim 2 \%$ isoflurane. Regular blood gas measurements confirmed physiologic ventilation and oxygenation.

\section{Study Design}

The sheep were acclimatized for more than 2 weeks before randomization into 2 groups. Selective percutaneous over-the-wire catheterization of the main septal perforating artery (MSPA) was followed by either sham or active percutaneous transluminal septal myocardial ablation of the artery (PTSMA). ${ }^{17}$ After 4 weeks of recovery, the RV hemodynamic and dimensional changes were measured in response to custom-designed HeartPatch DCC placement and its actuation in 5 modes: no device use, passive placement of the DCC device, and LV, RV, or biventricular actuation. ${ }^{15,18}$

\section{Interventricular Septal Ablation}

For interventricular (IV) septal ablation, a 53-cm, transvenous, active fixation, bipolar pacemaker lead (Capsure SP-4524; Medtronic Corporation, Minneapolis Minn) was secured to the RV apex and connected to the Medtronic pacemaker (Sigma Series SR 300; Medtronic Corporation)
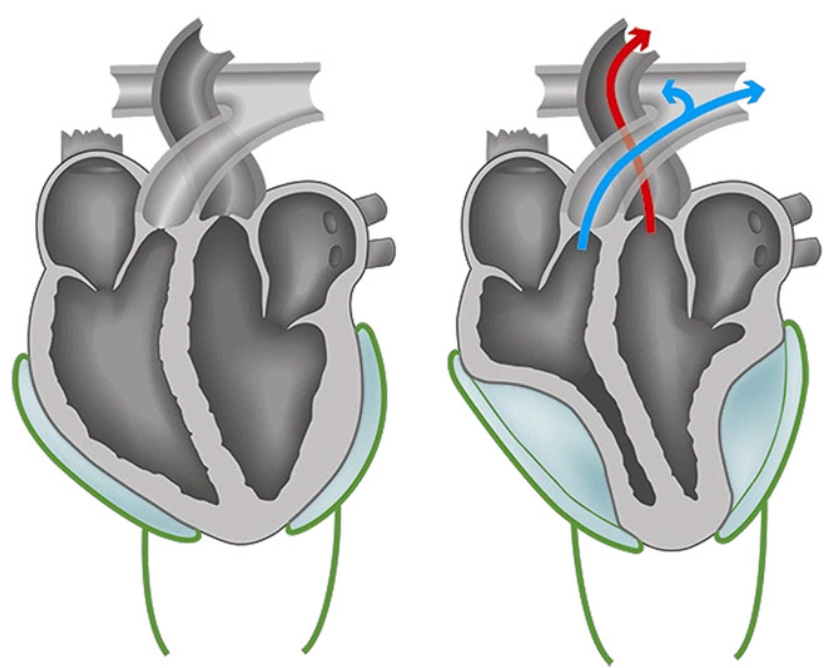

FIGURE 1. Diagrammatic representation of HeartPatch direct cardiac compression device. Each patch was designed to conform to either the left ventricular or right ventricular contour and consisted of a thin inner and thicker outer wall. The shape and mechanical properties of the walls were designed using finite element modeling to achieve maximal inward volume displacement during inflation.

set to activate at a hysteresis of $50 \mathrm{bpm}$ and pace at $80 \mathrm{ppm}$ as a rescue device for high-grade heart block. A $2.0 \times 9$-mm over-the-wire balloon catheter (Maverick SoftLEAP; Boston Scientific, Boston, Mass) mounted on a 0.014-in. hydrocoat guidewire (Hi Torque Balance Middleweight; Guidant, St Paul, Minn) was angiographically guided from the carotid artery into the MSPA with proximal clearance of the left anterior descending artery. Confirmed correct positioning of the balloon markers within the MSPA with angiographically verified arterial patency was considered completion of sham ablation. For septal ablation, a bolus volume of $0.6 \mathrm{~mL}$ $99.6 \%$ ethanol was delivered immediately after balloon inflation to 8 atm. At 10 minutes after balloon inflation, the catheter was removed, and MSPA closure was angiographically verified. The history of the pacemaker performance was checked 4 weeks later, followed by a terminal hemodynamic study, and the heart was harvested for histologic analysis. Confirmation of the ablation/infarction pathologic features followed selective MSPA perfusion using $1 \%$ triphenyltetrazolium solution and simultaneous differential staining through the left main and right coronary arteries. ${ }^{17}$

\section{Hemodynamic Instrumentation}

After cannulation of the left jugular vein and carotid artery, a transvenous $6 \mathrm{~F}$ Swan-Ganz catheter was advanced to the pulmonary artery and a $5 \mathrm{~F}$ Millar micromanometer-tipped catheter was placed in the RV. A $36 \mathrm{~F}$ Fogarty catheter placed in the inferior vena cava enabled transient occlusion. The heart and great vessels were accessed through a left thoracotomy with removal of the fifth rib. After incision of the pericardium from the apex to its reflection, Transonic flow probes (MA-16 and MA-20PAX; Transonic Systems, Natick, NY) were placed around the ascending aorta and pulmonary trunk. Ten digital, omnidirectional, transceiver sonomicrometer crystals (2-mm Silastic; Sonometrics, London, Ontario, Canada) were attached in the epicardial and endocardial positions. ${ }^{17}$ Other crystals were positioned in an equatorial plane across the cardiac short axis to measure the RV and LV internal dimension and the thickness of the LV, RV free wall, and septum. Their position was confirmed at autopsy.

\section{HeartPatch DCC Placement}

Drivelines for the HeartPatch DCC were passed through incisions in the pericardial apex and exited the subcostal space, inferior to the xiphisternum 


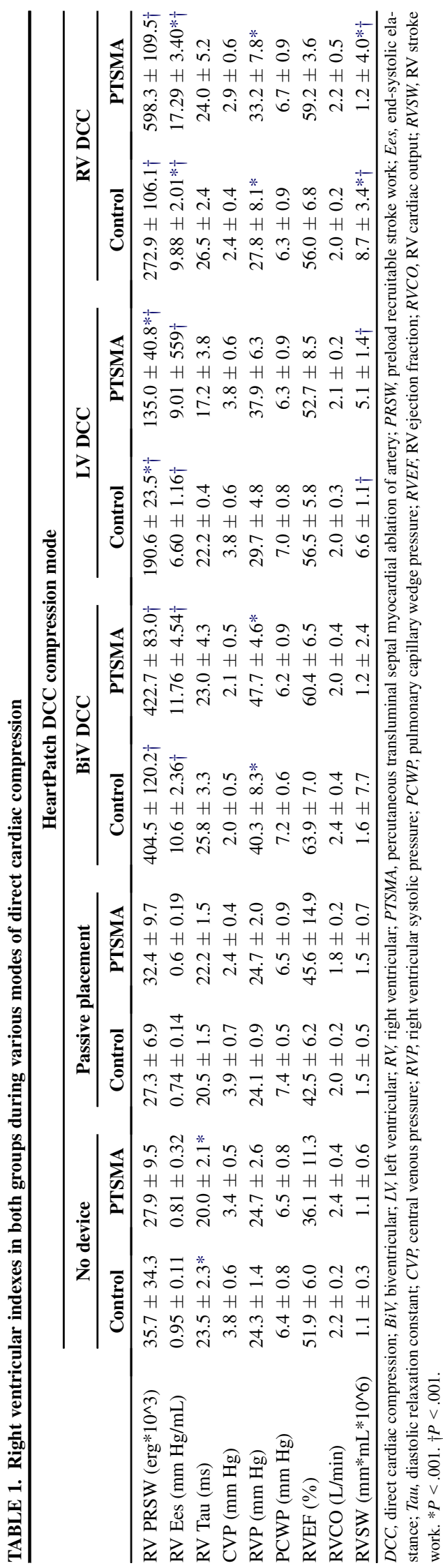

through two 8-mm midline incisions, and were connected to a customdesigned drive unit. The HeartPatch DCC epicardial surfaces were apposed to the respective ventricles, and their edges were secured to the posterior and anterior pericardium using 3-0 Proline sutures. The pericardium was loosely closed around the patches with a series of four 5-0 Proline interrupted sutures.

\section{Hemodynamic Measurements}

The hemodynamic measurements at end expiration after more than 30 minutes of stable anesthesia were as follows: (1) central venous pressure, pulmonary artery pressure, and pulmonary capillary wedge pressure (Swan-Ganz catheter); (2) RV systolic pressure (Millar pressure tip catheter); and (3) RV volume using sonomicrometers and an ellipsoid subtraction model, ${ }^{19}$ with the stroke volume calibrated against the pulmonary flow probe, (4) indexes of ejection fraction, RV stroke work, ${ }^{20} \mathrm{RV}$ end systolic elastance (Ees), RV preload recruitable stroke work (PRSW), ${ }^{21}$ and $\mathrm{RV}$ diastolic relaxation constant $(\mathrm{Tau})^{22}$ from integrated pressure and volume loop data using Conduct-PC software, version 2.3.1 (Cardiodynamics, Rijinsberg, The Netherlands), ${ }^{23}$ and (5) geometric measurements from raw sonomicrometric data.

\section{Data Analysis}

The RV internal septal-lateral end-diastolic (ED) and end-systolic (ES) short-axis dimensions were analyzed as previously described. ${ }^{17} \mathrm{ED}$ was defined as the interval of the peak electrocardiographic R wave and LV ES and RV ES as the point of zero aortic or pulmonary flow, respectively. Steady state hemodynamic parameters represented the average of 8 to 10 beats. An operator unaware of the treatment groups analyzed coded, randomized, digital, histologic photos by planimetry (Sigma Scan Image, version 2.03; SPSS, Chicago, Ill).

\section{Statistical Analysis}

The results are reported as the mean or percentage $\pm \mathrm{SD}$, as appropriate. For all parameters, the comparisons over time and between groups were calculated using repeated measures analysis of variance (SigmaStat Statistical Software, version 2.03; SPSS).

\section{RESULTS}

Of the 15 sheep studied, 12 were used for the analysis; 6 in the septal ablation group and 6 in the control group. Of the remaining 3 sheep, 2 had died acutely of heart failure and/ or irrecoverable arrhythmias after PTSMA and 1 was killed after embolization of a fractured angiowire fragment.

\section{Load-Independent Systolic and Diastolic Function}

The RV PRSW, RV Ees, and RV Tau patterns (Table 1 and Figure 2) were affected by the mode of DCC assist used $(P<0.001)$ and the presence of IV septal infarction (PTSMA, $P<.001$ ). The RV PRSW and Ees pattern across various implementations of DCC showed that all forms of active DCC improved the RV functional indexes.

A proportionally greater increase occurred in the RV PRSW index during LV DCC in the control sheep compared with the study sheep $(190.6 \pm 23.5$ vs $135.0 \pm 40.8$ $\left.\mathrm{erg}^{*} 10^{\wedge} 3\right)$. In contrast, a proportionally greater increase occurred in the RV Ees in the PTSMA sheep during RV DCC than in the control sheep $(17.29 \pm 3.40 \mathrm{vs} 9.88 \pm 2.01 \mathrm{~mm}$ $\mathrm{Hg} / \mathrm{mL}$, respectively). Before device placement, the RV Tau 


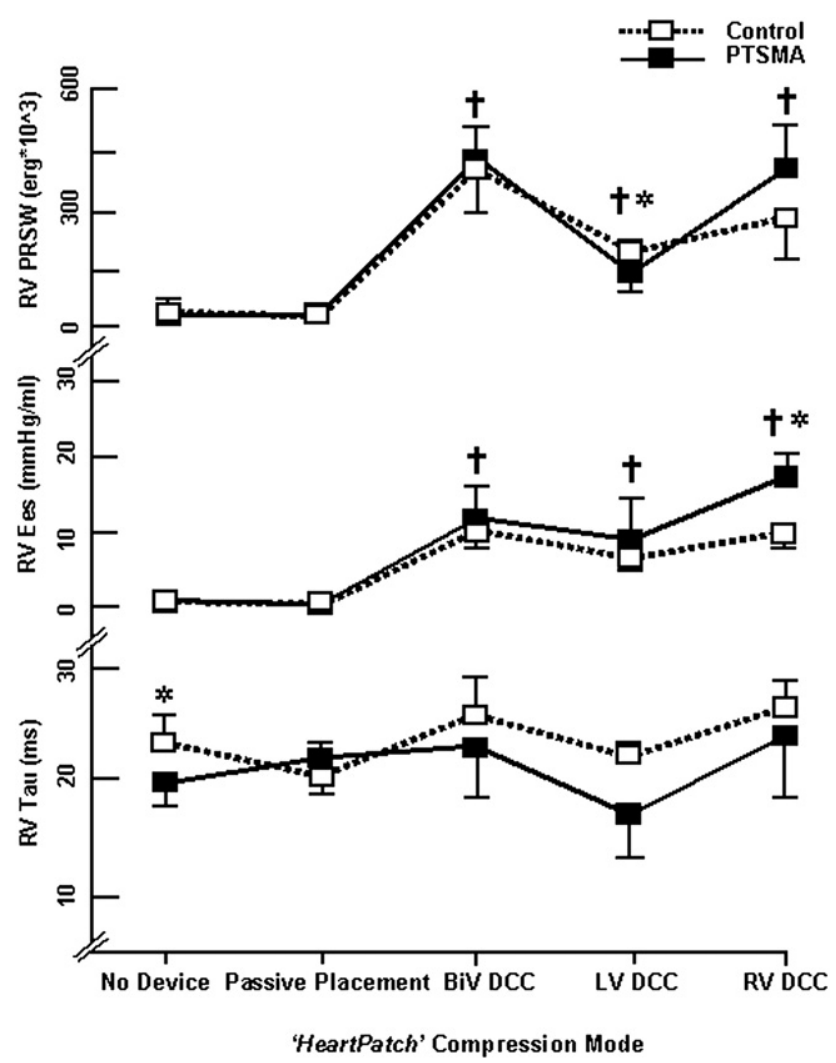

FIGURE 2. Load-independent hemodynamic effects of direct cardiac compression $(D C C)$ in control and percutaneous transluminal septal myocardial ablation of the artery (PTSMA) sheep. RV PRSW, right ventricular preload recruitable stroke work; $R V E e s$, right ventricular end-systolic elastance; $R V T a u$, right ventricular diastolic relaxation constant; $B i V$, biventricular. $(\dagger P \leq .01$ compared with no-device value; $* P \leq .01$, PTSMA vs control). Note: active modes of DCC increased right ventricular systolic pressure, right ventricular stroke work, and RV Ees. Compared with control group, PTSMA group had increased Ees during RV DCC and decreased PRSW during LV DCC. No significant differences seen between control and PTSMA sheep in any of remaining indexes or DCC modes.

was lower in the PTSMA sheep than in the control group $(20.0 \pm 2.1$ vs $23.5 \pm 2.3 \mathrm{~ms})$, a difference no longer observed in any of the compression modes.

\section{Load-Dependent RV Function}

The load-dependent hemodynamic data are listed in Table 1 and shown in Figures 3 and 4. The RV systolic pressure, PCWP, and RV stroke work (SW) patterns were affected by DCC assist $(P<.001)$ and the presence of IV septal infarction (PTSMA). The biventricular DCC and RV DCC increased the RV systolic pressure to a greater extent in the PTSMA group than in the control group $(47.7 \pm 4.6$ vs $37.9 \pm 6.3 \mathrm{~mm} \mathrm{Hg}$ and $40.3 \% \pm 8.3 \%$ vs $29.7 \% \pm 4.8 \%$, respectively). Furthermore, the generated RV SW was greater during LV DCC in the control sheep and during RV DCC in the PTSMA sheep $(6626 \pm 1107$

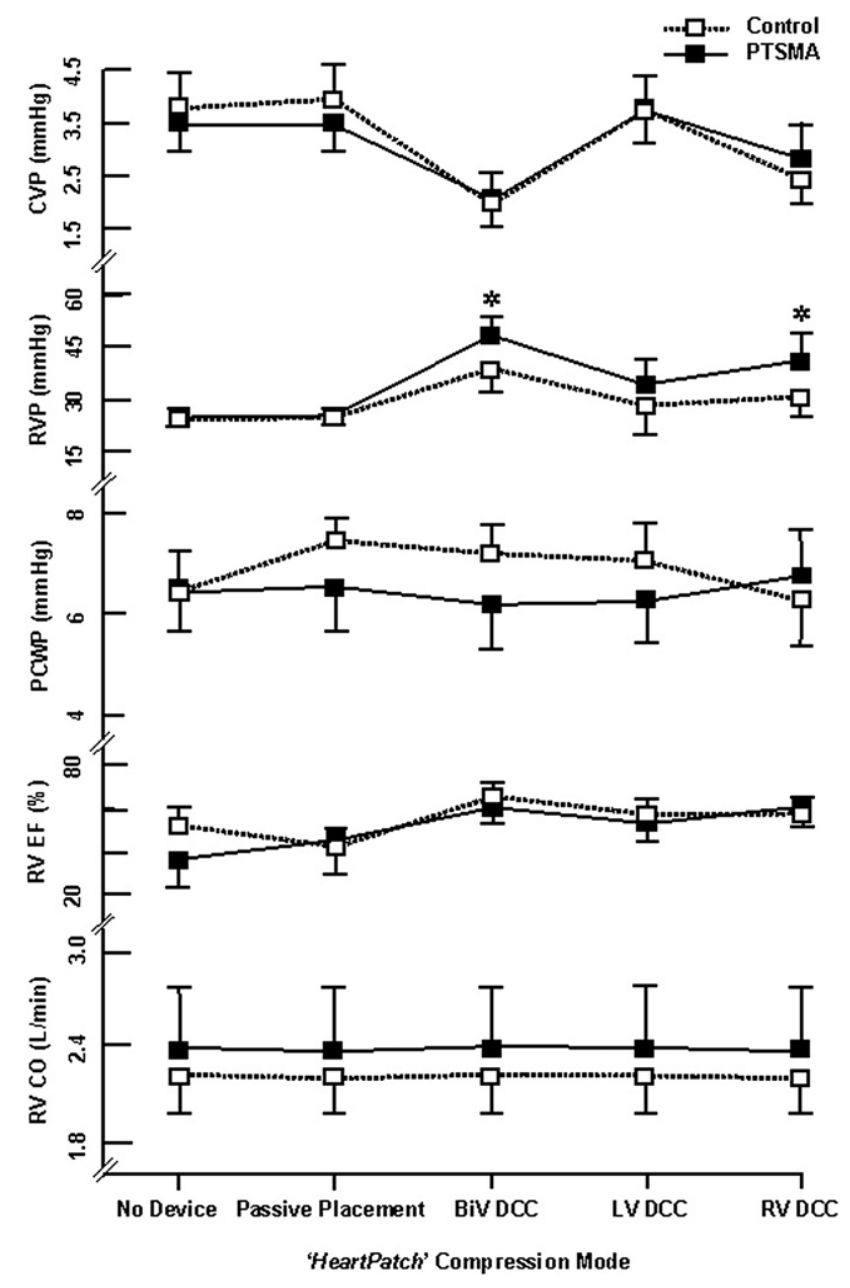

FIGURE 3. In-series hemodynamic effects of direct cardiac compression $(D C C)$ in control and percutaneous transluminal septal myocardial ablation of the artery (PTSMA) sheep. Control group demonstrated greater right ventricular systolic pressure $(R V P)$ during biventricular $(B i V)$ DCC and left ventricular $(L V)$ DCC compared with PTSMA sheep. $C V P$, central venous pressure; $P C W P$, pulmonary capillary wedge pressure; $R V E F$, right ventricular ejection fraction; $R V C O$, right ventricular cardiac output. $* P \leq .01$, PTSMA vs control group.

vs $5104 \pm 1411 \mathrm{~mm} \mathrm{Hg*mL}$ and $12,438 \pm 4006$ vs 8712 $\pm 3416 \mathrm{~mm} \mathrm{Hg} * \mathrm{~mL}$, respectively; Figure 4).

\section{Dimensional Changes}

The RV internal septal-lateral short-axis dimension response to DCC is summarized in Table 2.

The fractional change of the RV ED to RV ES dimension was reduced during LV DCC actuation to a greater degree in the control sheep (ED 98.2\% $\pm 5.0 \%$ to ES $70.1 \% \pm$ $15.9 \%=28.6 \%$ change; $\mathrm{ED} 98.9 \% \pm 5.6 \%$ to $\mathrm{ES}$ $90.5 \% \pm 5.0 \%=9.0 \%$ change, $*, P<.001)$. In contrast, it was reduced to a greater degree during RV DCC in the PTSMA sheep (ED $125.7 \% \pm 25.0 \%$ to ES $50.1 \% \pm$ $12.6 \%=60.1 \%$ change; $\mathrm{ED} 122.1 \% \pm 12.4 \%$ to $\mathrm{ES}$ 


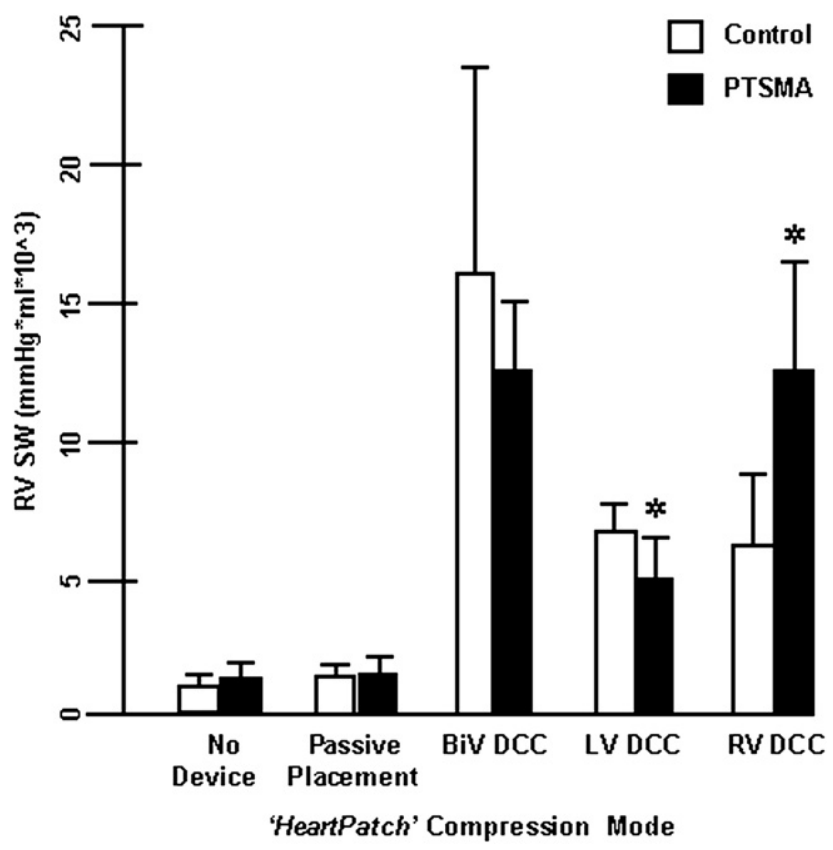

FIGURE 4. Effect of variable modes of HeartPatch direct cardiac compression $(D C C)$ on right ventricular $(R V)$ stroke work $(S W)$. RV SW during left ventricular $(L V)$ DCC was greater in control group but was greater in PTSMA group during RV DCC. $* P \leq .01$, PTSMA vs control.

$63.4 \% \pm 14.2 \%=48.1 \%$ change, $*, P<.001)$. No other difference was found between the 2 groups.

\section{DISCUSSION}

The major findings of the present study were first that the presence of IV septal infarction altered the effect of various DCC modes. Second, HeartPatch DCC device placement within the pericardial cavity did not affect systolic or diastolic function. Third, bi- and univentricular assist both led to a substantial increase in cardiac output and a lowering of the central venous pressure, irrespective of IV septal damage. Fourth, bi- and univentricular DCC actuation both augmented the native Frank-Starling response, as demonstrated by a marked increase in the PRSW. This brings into question current opinion. Fifth, RV DCC actuation increased load-independent RV function in excess of LV actuation. Finally, the effect of LV DCC actuation using compressive energy delivery was curtailed in the presence of IV septal infarction but enhanced when the right patch was also actuated.

\section{Load-Independent Response of RV to DCC}

The load-independent results of the present study have added significant credibility to its findings with the use of DCC, with markedly increased PRSW and Ees from both bi- and univentricular RV compression compared with isolated LV actuation (Table 1 and Figure 2). This RV response has demonstrated that the HeartPatch DCC engages a Frank-Starling relationship in response to altering preload, as evidenced by an increase in the slope of the ES pressure/volume relationship (ESPVR), a phenomenon not previously described.

A parallel shift in the ESPVR with an unaltered slope (elastance-Ees) has been the previously predicted response to DCC, ${ }^{24,25}$ where on external compression of the heart, the dynamic ventricular volume window shifts to the left, creating a new equilibrium of smaller ED and ES volumes. The slope of the ESPVR (Ees) will remain constant, and the predicted volume at $0 \mathrm{~mm} \mathrm{Hg}$ ("V0") will be reduced. The physiologic F-S response within the native myocardium entails a minimally altered ES volume, an increased ED volume (with an increase in stroke volume), and an increase in cardiac output. The slope of the ESPVR (Ees) increases proportionally, indicative of enhanced contractility.

For this response to manifest during dynamic DCC, the mechanical compression must be capable of responding to increased venous return. This translates to enhanced epicardial compressive pressure delivery as the volume increases. Such external compressive engagement of the FrankStarling mechanism has only been previously observed with dynamic cardiomyoplasty. ${ }^{26-28}$

Our results have demonstrated that this dynamic enhancement capability also extends to the HeartPatch DCC device, with Ees increasing from 0.8 to $11 \mathrm{~mm} \mathrm{Hg} / \mathrm{mL}$ with biventricular DCC. We propose that this relates to the device's "nonsurround" design, aimed at removing the constrictive effects of its "heart-surround" counterparts.

\section{Load-Dependent and RV Diastolic Response to DCC}

Although the RV systolic pressure increased in both experimental groups, the biventricular and single-RV

TABLE 2. Right ventricular septal to lateral wall distances at end-diastole and end-systole in both groups during various modes of HeartPatch DCC

\begin{tabular}{|c|c|c|c|c|c|c|c|c|c|c|}
\hline \multirow{3}{*}{$\begin{array}{l}\text { RV septal-lateral } \\
\text { short axis } \\
\text { dimension (\%) } \\
\end{array}$} & \multicolumn{10}{|c|}{ HeartPatch DCC compression mode } \\
\hline & \multicolumn{2}{|c|}{ No device } & \multicolumn{2}{|c|}{ Passive placement } & \multicolumn{2}{|c|}{ BiV DCC } & \multicolumn{2}{|c|}{ LV DCC } & \multicolumn{2}{|c|}{ RV DCC } \\
\hline & ED & ES & ED & ES & ED & ES & ED & ES & ED & ES \\
\hline Control & $100 \pm 0$ & $100 \pm 0$ & $98.4 \pm 3.3$ & $98.4 \pm 6.1$ & $120.6 \pm 9.7$ & $55.9 \pm 11.5$ & $98.2 \pm 5.0$ & $70.1 \pm 15.9^{*}$ & $122.1 \pm 12.4$ & $63.4 \pm 14.2$ \\
\hline PTSMA & $100 \pm 0$ & $100 \pm 0$ & $99.5 \pm 2.4$ & $100.6 \pm 4.8$ & $113.6 \pm 10.0$ & $47.4 \pm 10.1$ & $98.9 \pm 5.6$ & $90.5 \pm 5.0$ & $125.7 \pm 21.0$ & $50.1 \pm 12.6^{*}$ \\
\hline
\end{tabular}


DCC actuation caused a greater increase in the heart with septal ablation (Table 1 and Figure 2). No other differences in the load-dependent indexes were observed between the control sheep or those with an infarcted IV septum. Given the greater RV systolic pressure in the IV septum-ablated sheep after RV patch actuation, septal fibrosis appeared to lessen the translational loss of pressure to the LV owing to a "buttressing" effect, which confined the bulk of DCC energy delivery to the RV. Additional support for this premise was reflected in the greater RV SW values seen in the IV septal-ablated sheep during RV patch actuation, which also explains, by way of reciprocation, the lower RV SW values observed in the PTSMA sheep during univentricular LV DCC (Figure 4). Our previous studies have shown that cardiomyoplasty can also enhance external SW. ${ }^{28}$

We have previously shown, under closed chest conditions, that PTSMA alone leads to prolonged Tau. ${ }^{17}$ However, we did not observe this in the present study, in which Tau was paradoxically reduced by IV septal ablation. The difference most likely reflects the effect of pericardiotomy in an open chested animal.

Despite the likelihood of diastolic interference from DCC surround devices, this issue has not received significant attention. ${ }^{12}$ The initial concerns about the potential tamponade using the HeartPatch device were overcome by placement of a series of longitudinal pericardial incisions.

\section{Geometric Response to DCC}

The aim of DCC is to provide hemodynamic stabilization by enhancing the approximation of heart contractile elements in all 3 geometric axes. Our previous work showed that the HeartPatch DCC device increased the lateral short-axis fractional change during systole. However, during normal systolic contraction, in which reduction in the anterior-posterior axis would be expected, paradoxic lengthening was found with DCC. ${ }^{18}$ Cavity volume reduction was achieved because the septal-lateral short-axis change exceeded the anterior-posterior lengthening.

The only significant differences between the IV septalablated and control sheep were in the relative reductions of the RV ES dimension in the former during RV DCC and the latter during LV DCC. The enhanced systolic benefit during RV DCC and the reduced benefit during LV DCC in the PTSMA sheep were most likely a result of chamber containment of energy delivery during RV DCC and decreased transmission of LV free wall compression brought about by a stiffened, fibrosed septum. It is clear from our results that even though the IV septal diastolic position remains unaffected, the ES septal-lateral dimension will be decreased with all modes of DCC actuation. This was shown by an increase in the fractional change of the endocardial septal-lateral RV dimension.

\section{Study Limitations}

The effects of DCC were assessed using an open chest model. It is possible that the hemodynamic effects of intrapericardially placed devices in a closed chest model would be different. Furthermore, the hemodynamic effects of DCC were only measured from minutes to hours.

Heart function was assessed in an experimental model designed to address specific physiologic questions, rather than a heart failure model, to reduce potential confounders. Thus, we have not applied the septal injury model to a failing heart.

The present study was designed to assess the RV functional response to DCC to compare it with previous investigations of LV unloading devices. ${ }^{35}$ The LV response to DCC was not addressed. We have indirectly suggested that PTSMA reduces translational energy delivery through IV septal tissue during univentricular DCC by observation of the relative differences in RV SW, systolic pressure, and dimensional changes during LV/RV DCC. To confirm this premise, investigations of comparative LV indexes are needed.

\section{CONCLUSIONS}

The HeartPatch DCC device conferred effective RV support and maintained RV function, irrespective of chronic septal damage, with evidence of recruitment of a FrankStarling relationship. This contrasts with the traditional flow-through LV unloading devices. Furthermore, diastolic impairment was not evident under open chest conditions.

Device-based advances in the treatment of heart failure have recently included minimally invasive LVAD axial flow devices, ${ }^{5,29}$ LVAD endovascular coatings, ${ }^{30}$ improvements in total artificial heart design, ${ }^{31,32}$ and cardiac resynchronization therapy. ${ }^{33,34}$ DCC forms of cardiac assist have the potential to provide effective $\mathrm{LV}$ and $\mathrm{RV}$ support, particularly in cases in which RV dysfunction is commonly induced after placement of an LV unloading device for severe heart failure.

We thank Mr Bruce Williams, the late Mr Ray Kearns, Mr Wayne Roach, Ms Cathy Mundy, and Ms Kellie Tinworth for technical assistance. Also, Medtronic Inc, which, by way of Mr Chris McLure, supplied and advised on the use of the pacemakers.

\section{References}

1. Hunt SA. Mechanical circulatory support: new data, old problems. Circulation. 2007; 116:461-2.

2. Lietz K, Long JW, Kfoury AG, Slaughter MS, Silver MA, Milano CA, et al. Outcomes of left ventricular assist device implantation as destination therapy in the postREMATCH era: implications for patient selection. Circulation. 2007;116:497-505.

3. Drakos SG, Charitos EI, Nanas SN, Nanas JN. Ventricular-assist devices for the treatment of chronic heart failure. Exp Rev Cardiovasc Ther. 2007;5:571-84.

4. Maybaum S, Mancini D, Xydas S, Starling RC, Aaronson K, Pagani FD, et al. Cardiac improvement during mechanical circulatory support: a prospective multicenter study of the LVAD Working Group. Circulation. 2007;115:2497-505.

5. Lietz K, Miller LW. Destination therapy: current results and future promise. Semin Thorac Cardiovasc Surg. 2008;20:225-33.

6. Sayer G, Naka Y, Jorde UP. Ventricular assist device therapy. Cardiovasc Therapeut. 2009;27:140-50. 
7. Matthews JC, Koelling TM, Pagani FD, Aaronson KD. The right ventricular failure risk score: a pre-operative tool for assessing the risk of right ventricular failure in left ventricular assist device candidates. J Am Coll Cardiol. 2008;51:2163-72.

8. Stone ME. Current status of mechanical circulatory assistance. Semin Cardiothorac Vasc Anesth. 2007;11:185-204.

9. Furukawa K, Motomura T, Nose Y. Right ventricular failure after left ventricular assist device implantation: the need for an implantable right ventricular assist device. Artif Organs. 2005;29:369-77.

10. Morgan JA, John R, Lee BJ, Oz MC, Naka Y. Is severe right ventricular failure in left ventricular assist device recipients a risk factor for unsuccessful bridging to transplant and post-transplant mortality. Ann Thorac Surg. 2004;77:859-63.

11. McDonald MA, Ross HJ. Trying to succeed when the right ventricle fails. Curr Opin Cardiol. 2009;24:239-45.

12. Oz MC, Artrip JH, Burkhoff D. Direct cardiac compression devices. J Heart Lung Transplant. 2002;21:1049-55.

13. Anstadt MP, Schulte-Eistrup SA, Motomura T, Soltero ER, Takano T, Mikati IA, et al. Non-blood contacting biventricular support for severe heart failure. Ann Thorac Surg. 2002;73:556-62.

14. Williams MR, Artrip JH. Direct cardiac compression for cardiogenic shock with the CardioSupport system. Ann Thorac Surg. 2001;71:S188-9.

15. Gallagher GL, Huang YF, Morita S, Zielinski RR, Hunyor SN. Efficacy and mechanisms of biventricular and left/right direct cardiac compression in acute heart failure sheep. Artif Organs. 2007;31:39-44.

16. Carrington RA, Huang Y, Kawaguchi O, Yuasa T, Shirota K, Martin D, et al. Direct compression of the failing heart reestablishes maximal mechanical efficiency. Ann Thorac Surg. 2003;75:190-6.

17. Mau JC, Menzie SJ, Ward MR, Bundgaard H, Hunyor SN. Time-dependent response of both ventricles after septal ablation: implications for biventricular support after left ventricular assist device placement. J Thorac Cardiovasc Surg. 2007;134:579-86

18. Gallagher GL, Huang YF, Zielinski R, Morita S, Hunyor SN. Effect of direct cardiac compression on left ventricular axial dynamics in sheep. ASAIO J. 2007;53: 292-7.

19. Feneley MP, Elbeery JR, Gaynor JW, Gall SAJ, Davis JW, Rankin JS. Ellipsoidal shell subtraction model of right ventricular volume: comparison with regional free wall dimensions as indexes of right ventricular function. Circ Res. 1990;67:1427-36.

20. Nicolosi AC, Hettrick DA, Warltier DC. Assessment of right ventricular function in swine using sonomicrometry and conductance. Ann Thorac Surg. 1996;61: 1381-8.

21. Danton M, Greil G, Byrne J, Hsin M, Cohn L, Maier S. Right ventricular volume measurement by conductance catheter. Am J Physiol Heart Circ Physiol. 2003; 285:H1774-85.
22. Leeuwenburgh BPJ, Steendijk P, Helbing WA, Baan J. Indexes of diastolic RV function: load dependence and changes after chronic RV pressure overload in lambs. Am J Physiol. 2002;282:H1350-8.

23. Ramanathan T, Shirota K, Morita S, Nishimura T, Huang Y, Hunyor SN. Glucose-insulin-potassium solution improves left ventricular mechanics in diabetes. Ann Thorac Surg. 2002;73:582-7.

24. Artrip JH, Yi GH, Levin HR, Burkhoff D, Wang J. Physiological and hemodynamic evaluation of nonuniform direct cardiac compression. Circulation. 1999; 100:II236-43

25. Artrip JH, Wang J, Leventhal AR, Tsitlik JE, Levin HR, Burkhoff D. Hemodynamic effects of direct biventricular compression studied in isovolumic and ejecting isolated canine hearts. Circulation. 1999;99:2177-84.

26. Shirota K, Huang Y, Kawaguchi O, Yuasa T, Brady PW, Ueda Y, et al. Functional recovery of the native heart after cardiomyoplasty in sheep with heart failure: passive and dynamic effects of volume loading. Ann Thorac Surg. 2002;73 849-54.

27. Kawaguchi O, Huang YF, Yuasa T, Shirota K, Carrington RA, Hunyor SN Cardiomyoplasty reduces myocardial oxygen consumption: implications for direct mechanical compression. Ann Thorac Surg. 2002;74:1092-7.

28. Kawaguchi O, Huang Y, Yuasa T, Horam CJ, Carrington RA, Biao Z, et al. Improved efficiency of energy transfer to external work in chronic cardiomyoplasty based on the pressure-volume relationship. J Thorac Cardiovasc Surg. 1998;115 1358-66.

29. Selzman CH, Chang PP, Vernon-Platt T, Bowen A, Kowalczyk S, Sheridan BC Use of the Jarvik 2000 continuous flow left ventricular assist device for acute myocardial infarction and cardiogenic shock. J Heart Lung Transplant. 2007; 26:756-8.

30. Sin DC, Kei HL, Miao X. Surface coatings for ventricular assist devices. Exp Rev Med Devices. 2009;6:51-60.

31. Ueno A, Tomizawa Y. Cardiac rehabilitation and artificial heart devices. J Artif Organs. 2009;12:90-7.

32. Morris RJ. Total artificial heart: concepts and clinical use. Semin Thorac Cardiovasc Surg. 2008;20:247-54.

33. Jessup M. MADIT-CRT: breathtaking or time to catch our breath?-editorial N Engl J Med. 2009;361:1394-6.

34. Williams L, Ellery S, Patel K, Leyva F, Bleasdale R, Phan T, et al. Short-term hemodynamic effects of cardiac resynchronization therapy in patients with hear failure, a narrow QRS duration, and no dyssynchrony. Circulation. 2009;120: 1687-94.

35. Mau JC, Menzie SJ, Huang Y, Ward MR, Hunyor SN. Chronic septal infarction confers right ventricular protection during mechanical left ventricular unloading. J Thorac Cardiovasc Surg. 2009;138:172-8. 